\title{
Management of colonic volvulus
}

\author{
Ahmed M Kamal, MD; Mahmoud Saad, MD \\ Department of General Surgery, Ain Shams University, Cairo, Egypt.
}

\begin{abstract}
Aim: Colonic volvulus is defined as an axial twist of part of the colon along its mesentery of which sigmoid volvulus is the most common \& splenic flexure volvulus is the least common. The purpose of this study is to evaluate the clinical features and surgical treatment methods in patients with colonic volvulus.

Method: Thirty-six patients operated upon between April 2007 and Mars 2010 were reviewed retrospectively. The demographic data of the patients, clinical features, preoperative radiological and operative findings, type of surgical procedure performed, postoperative complications, mortality and duration of hospital stay after surgery were reviewed.

Results : There were 26 male (72\%), 10 female patients (28\%) and their age ranged from 28 to 72 years with a mean of $53 \pm 7.8$ years. Most frequent clinical features were abdominal pain, distension and constipation by order of frequency. Hypertension was the most frequent co-morbidity. WBCs were elevated in 32 patients. Plain X-ray was done routinely in every patient with +ve results in 28 patients $(77 \%)$ \& contrast enema was done in 6 patients only. Emergent surgical treatment done in patients with manifestations of peritonitis (30pt, 83\%). Intra-operative, sigmoid volvulus was found in 30 pts, caecal volvulus in 3 patients, transverse colon volvulus in 2 pts and one case of splenic flexure volvulus. Decision for operation (Untwisting \& fixation $(n=3)$, resection \& primary anastomosis $(n=10)$, resection, anastomosis \& covering stoma $(n=11)$ and resection \& colostomy $(n=12)$, was dependent on intestinal viability, general condition of patient and surgeon's preference. Post operative hospital stay ranged from 5 days to 26 days. It was least in patients underwent resection, anastomosis \& covering stoma $8 \pm 4.11$

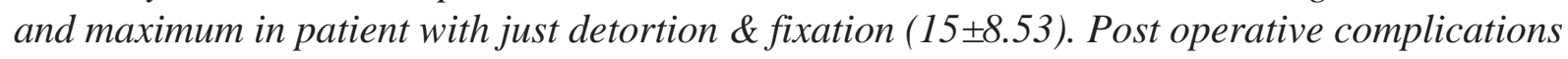
included post-operative, anastomotic leakage, wound infection, re-operation (Recurrent obstruction) and pulmonary complications.

Conclusion: Identifying those patients at the onset of their clinical course of colonic volvulus entails a high index of suspicion \& resection with or without primary anastomosis should be the basic principle in management of colonic volvulus as detorsion and fixation carry a high risk of recurrence of the volvulus

Key words: Colon volvulus, management
\end{abstract}

\section{Introduction:}

Volvulus is defined as an abnormal twisting of a segment of bowel on itself, along its longitudinal axis. This results in occlusion of the proximal bowel and a closed loop obstruction within the segment. Compromised blood supply to the involved segment, together with the increase in intraluminal pressure, leads to gangrene and perforation if unrelieved. ${ }^{1}$ The incidence of colonic volvulus varies in different parts of the world. In the United States and
Great Britain volvulus accounts for approximately $1 \%$ to $7 \%$ of all cases of large bowel obstruction. ${ }^{2}$ In some west African states volvulus is responsible for $20 \%$ to $50 \%$ of intestinal obstructions. ${ }^{3}$ Sigmoid volvulus is the most common accounting for $75 \%$ of colonic volvulus. On the contrary, splenic flexure volvulus is the least common \& it was first reported in 1954 by Buenger. ${ }^{4}$ The diagnosis of colonic volvulus is determined from history, physical examination and careful 
interpretation of the plain abdominal radiographs. The correct preoperative diagnosis and early management of these patients is essential to achieve a good outcome. If the volvulus is not promptly relieved, the vascular supply to the bowel is affected, leading eventually to necrosis, perforation, septic shock, and death. ${ }^{5}$

Various surgical procedures have been advocated for colonic volvulus such as resection with primary anastomosis, resection with colostomies, tube colostomy, laparoscopyassisted colectomy, and extraperitonealization of part of colon. 6-10 In this retrospective study, we evaluated the clinical features, the predisposing factors, the surgical treatment methods and the main postoperative complications of patients with colonic volvulus.

\section{Patients and methods:}

Thirty-six patients with colonic volvulus admitted to the Department of General Surgery of Ain shams University Hospital, Faculty of Medicine between April 2007 and Mars 2010 were reviewed retrospectively. The medical records of age, gender, main symptoms and duration, physical examination findings, preoperative laboratory, radiological and operative findings, type of surgical procedure performed, postoperative complications, mortality and duration of hospital stay after surgery were reviewed for all patients. Patients with signs of peritonitis and perforation or unrelieved by passage of rectal tube were operated on urgently while patients without signs of peritonitis and perforation and those who were relieved with a trial of conservative treatment by passage of rectal tube were operated on electively within the same hospital admission. All patients were on 3rd generation cephalosporin and metronidazole. All patients were subjected to general anesthesia \pm epidural anesthesia. Critically ill patients were admitted to ICU either after operation or before \& after operation. Depending on the condition of the patients and the preference of the surgeons, surgical treatment consisted of resection and primary anastomosis, sigmoidectomy with either Hartmann's procedure or Paul-Mikulicz procedure colostomies, and operative detorsion with fixation. Follow-up data were obtained from medical records to assess late complications and recurrence rate. The mean follow-up periods were $12,24 \pm 7.56$ months (range 6-22 months).

\section{Statistical method:}

The collected data were analyzed using SPSS program (Statistical Package for Social Sciences) software version 17.0.

Descriptive statistics were done for numerical parametric data as mean, standard deviation and minimum $\&$ maximum of the range while they were done for categorical data as number and percentage.

Inferential analyses were done for quantitative variables using independent $t$-test in cases of two independent groups with parametric data. Inferential analyses were done for qualitative data using Chi square test for independent variables.

The level of significance was taken at $\mathrm{P}$ value -0.050 is significant, otherwise is non significant

\section{Results:}

Descriptive study was conducted, 36 patients were included in the study. There were 26 males $(72 \%)$ and 10 females $(28 \%)$. The mean age was $53 \pm 7.8(28-72)$ years.

Table (1):Demographics.

\begin{tabular}{|l|l|l|}
\hline Age (mean, SD, Range) & $53 \pm 7.8(28-72)$ \\
\hline Sex $\quad \begin{array}{l}\text {... male } \\
\text {... female }\end{array}$ & 26 & $72 \%$ \\
\cline { 2 - 3 } & 10 & $28 \%$ \\
\hline
\end{tabular}


Table (2): Clinical picture, other co-morbidities \& laboratory investigations.

\begin{tabular}{|c|c|c|}
\hline Clinical picture: & No. & Percentage \\
\hline Onset of symptoms & \multicolumn{2}{|c|}{1 days to 3 weeks (mean $5.2 \pm 0.73$ days) } \\
\hline Acute abdominal pain & 36 & $100 \%$ \\
\hline Abdominal distention & 34 & $95 \%$ \\
\hline Constipation & 32 & $89 \%$ \\
\hline Nausea \& vomiting & 10 & $28 \%$ \\
\hline Bleeding/rectum & 1 & $3 \%$ \\
\hline $\begin{array}{l}\text { On exam: tenderness \& rebound } \\
\text { tenderness (signs of peritonitis) }\end{array}$ & 30 & $83 \%$ \\
\hline \multicolumn{3}{|l|}{ Co morbidities } \\
\hline DM (diabetes mellitus) & 6 & $17 \%$ \\
\hline Hypertension & 12 & $33 \%$ \\
\hline ISHD (ischemic heart disease) & 8 & $25 \%$ \\
\hline Pulmonary disease & 5 & $14 \%$ \\
\hline \multicolumn{3}{|l|}{ Laboratory investigations: } \\
\hline Elevated WBCs $(\bullet 10.000)$ & 32 & $89 \%$ \\
\hline Anemia (Hb level $-10 \mathrm{gm} / \mathrm{dl})$ & 5 & $14 \%$ \\
\hline Renal impairment $(\mathrm{cr} \bullet 2 \mathrm{mg} / \mathrm{dl})$ & 6 & $17 \%$ \\
\hline
\end{tabular}

The common symptoms and signs are presented in Table(2) with pain is the leading urge for seek of medical consultation. The interval between onset of symptoms and admission ranged from 1 day to 21 days with mean5.2 \pm 0.73 days. On examination 30 patients had manifestations of peritonitis. Concomitant diseases listed with HTN are the most common. Laboratory investigations included CBC, PT\&PTT and blood chemistry. TLC was elevated in 32 patients $(89 \%)$.

\section{Table (3): Radiological investigations.}

\begin{tabular}{|l|l|l|}
\hline Radiological investigations & no & $\%$ \\
\hline Plain X-ray abdomen (erect, supine) (done for all pts) & & \\
.Multiple air fluid levels & 16 & $45 \%$ \\
.Coffee bean sign & 8 & $22 \%$ \\
.Free air under diaphragm (perforated colon) & 2 & $5 \%$ \\
.Large air fluid level at area of obstruction & 2 & $5 \%$ \\
.Indefinite findings & 8 & $23 \%$ \\
\hline Contrast enema (done for patients with no signs of peritonitis) & & \\
(6 patients only) (or after detorsion by rectal tube) & 1 & $3 \%$ \\
Splenic volvulus & 5 & $14 \%$ \\
Sigmoid volvulus & & \\
\hline
\end{tabular}


Plain X-ray abdomen erect \& supine was done for all patients, it gave us +ve findings in 28 patients in the form of multiple air fluid levels indicating intestinal obstruction, coffee bean sign which is diagnostic for twisted sigmoid colon in 8 patients (dilated air-filled bowel arising from the left lower quadrant and extending towards the diaphragm) and free air under diaphragm in 2 patients (perforated colon). Large air fluid level at area of obstruction was noted in 2 patients and indefinite findings in 8 patients.

Table (4): Intra operative findings \& treatment.

\begin{tabular}{|c|c|c|c|c|}
\hline \multirow{2}{*}{$\begin{array}{c}\text { Diagnosis } \\
(\mathrm{n}=36)\end{array}$} & \multicolumn{4}{|c|}{ Treatment } \\
\cline { 2 - 5 } & $\begin{array}{c}\text { Untwisting } \\
\text { fixation }\end{array}$ & $\begin{array}{c}\text { Resection } \\
\text { \& primary } \\
\text { anastomosis }\end{array}$ & $\begin{array}{c}\text { Resection, } \\
\text { anastomosis } \\
\text { \& covering stoma }\end{array}$ & $\begin{array}{c}\text { Resection } \\
\& \text { colostomy }\end{array}$ \\
\hline $\begin{array}{c}\text { Sigmoid } \\
\text { volvulus (n=30) }\end{array}$ & 3 & 5 & 10 & 12 \\
\hline $\begin{array}{c}\text { Splenic flexure } \\
\text { volvulus (n=1) }\end{array}$ & 0 & 1 & 0 & 0 \\
\hline $\begin{array}{c}\text { Transverse } \\
\text { colon volvulus (n=2) }\end{array}$ & 0 & 1 & 1 & 0 \\
\hline $\begin{array}{c}\text { Caecal volvulus } \\
(\mathrm{n}=3)\end{array}$ & 0 & 3 & 0 & 0 \\
\hline
\end{tabular}

Intra-operative diagnosis of sigmoid volvulus was the most common (30 pt), and Splenic flexure volvulus was the least (1 pt). Decision for operation [Untwisting \& fixation $(n=3)$, resection \& primary anastomosis $(n=10)$, resection, anastomosis \& covering stoma $(\mathrm{n}=11)$ and resection \& colostomy $(n=12)]$, was dependent on intestinal viability, general condition of patient and surgeon's preference.

Table (5):Post-operative complications \& follow-up (according to type of surgery).

\begin{tabular}{|l|c|c|c|c|c|}
\hline $\begin{array}{l}\text { Post-operative } \\
\text { complications }\end{array}$ & $\begin{array}{c}\text { Untwisting } \\
\text { \& fixation } \\
(\mathrm{n}=3)\end{array}$ & $\begin{array}{c}\text { Resection } \\
\text { \& primary } \\
\text { anastomosis } \\
(\mathrm{n}=10)\end{array}$ & $\begin{array}{c}\text { Resection, } \\
\text { anastomosis } \\
\text { \& covering } \\
\text { stoma (n=11) }\end{array}$ & $\begin{array}{c}\text { Resection } \\
\text { \&colostomy } \\
(\mathrm{n}=12)\end{array}$ & $\begin{array}{c}\text { Total } \\
20 / 36 \\
(56 \%)\end{array}$ \\
\hline Post-operative ileus & $\begin{array}{c}2 * \text { (statistically } \\
\text { significant) }\end{array}$ & 1 & 0 & 1 & 4 \\
\hline Anastomotic leakage & 0 & 1 & 1 & 0 & 2 \\
\hline $\begin{array}{l}\text { Wound infection } \\
\text { Re-operation } \\
\text { (Recurrent } \\
\text { obstruction) }\end{array}$ & 1 & 1 & 0 & $\begin{array}{c}5^{*} \text { (statistically } \\
\text { significant) }\end{array}$ & 7 \\
\hline $\begin{array}{l}\text { Pulmonary } \\
\text { complications }\end{array}$ & $\begin{array}{c}\text { significant) } \\
\text { (statistically }\end{array}$ & 1 & 0 & 0 & 3 \\
\hline $\begin{array}{l}\text { Mortality } \\
\text { host-operative } \\
\text { (days) mean } \pm S D\end{array}$ & $\begin{array}{c}15 \pm 8.53^{*} \\
\text { (statistically } \\
\text { significant) }\end{array}$ & $10 \pm 4.13$ & $8 \pm 4.11$ & $9 \pm 3.94$ & 3 \\
\hline
\end{tabular}


Post operative hospital stay ranged from 5 days to 26 days. It was least in patients who underwent resection, anastomosis \& covering stoma $8 \pm 4.11$ and maximum in patient with just detortion $15 \pm 8.53 *$ (statistically significant). Post-operative complications included post-operative ileus (maximum in $1^{\text {st }}$ group; untwisting; 2 ; statistically significant), anastomotic leakage, wound infection (maximum in last group; resection \& colostomy; 5; statistically significant), Reoperation (Recurrent obstruction) (maximum in 1st group; untwisting; 2; statistically significant), and pulmonary complications.

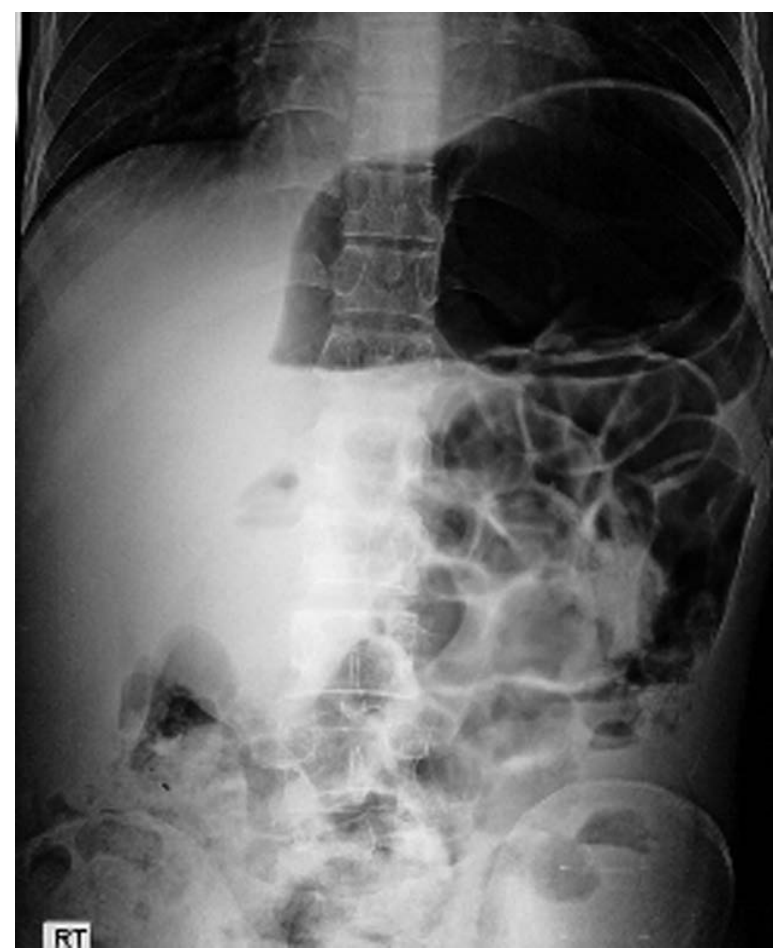

(A)

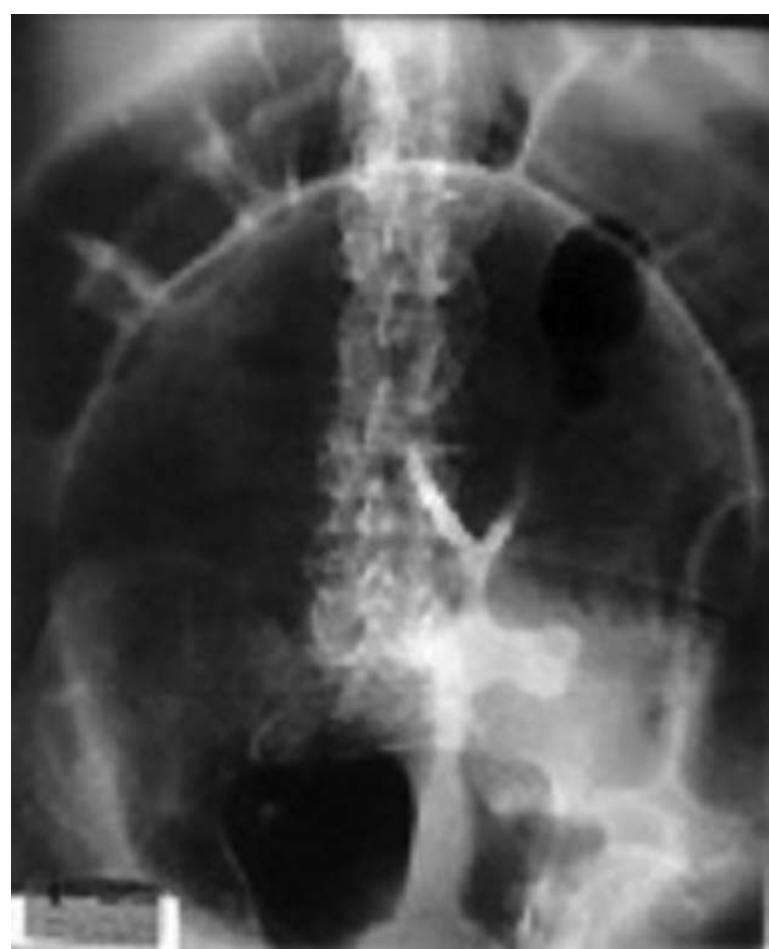

(B)

Figure (1): PXR abdomen A) Erect showing large air fluid level at left hypochondrium (splenic flexure volvulus) B) Supine showing coffee bean sign diagnostic of sigmoid volvulus.

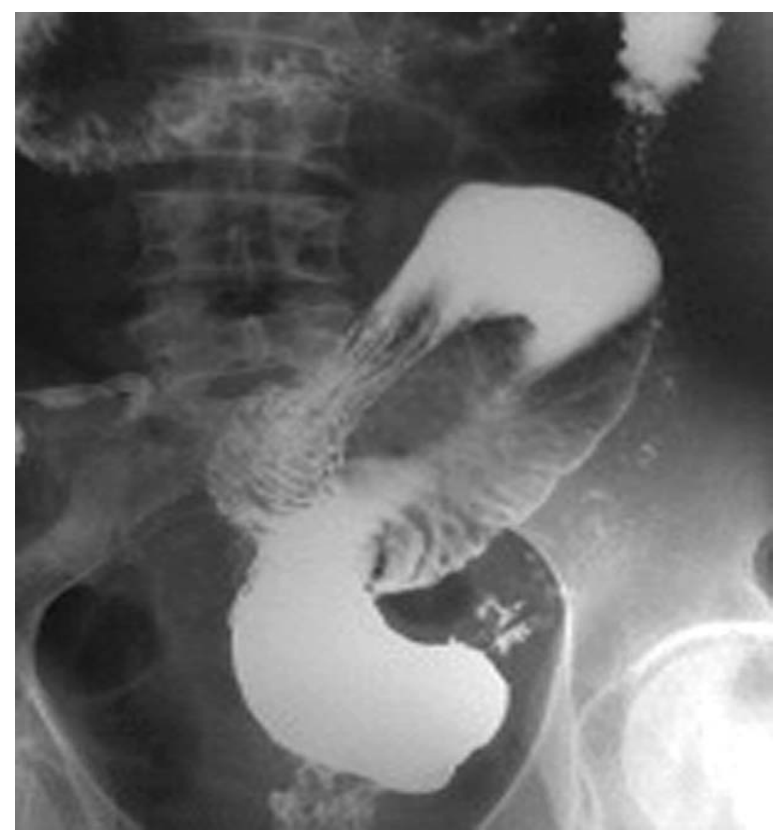

(A)

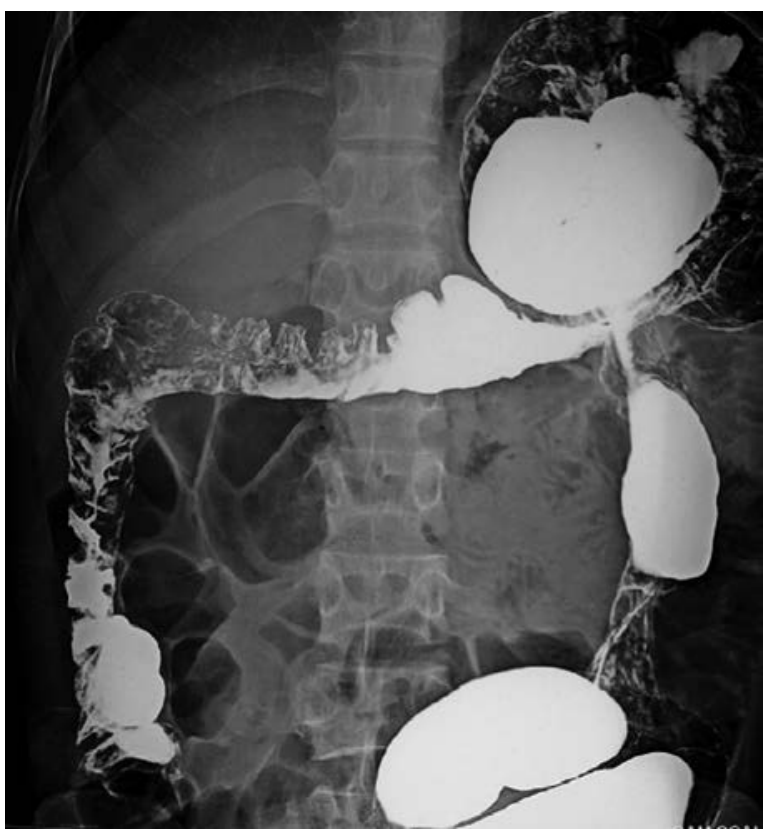

(B)

Figure (2): Contrast enema study A) Sigmoid volvulus B) Splenic flexure volvulus. 


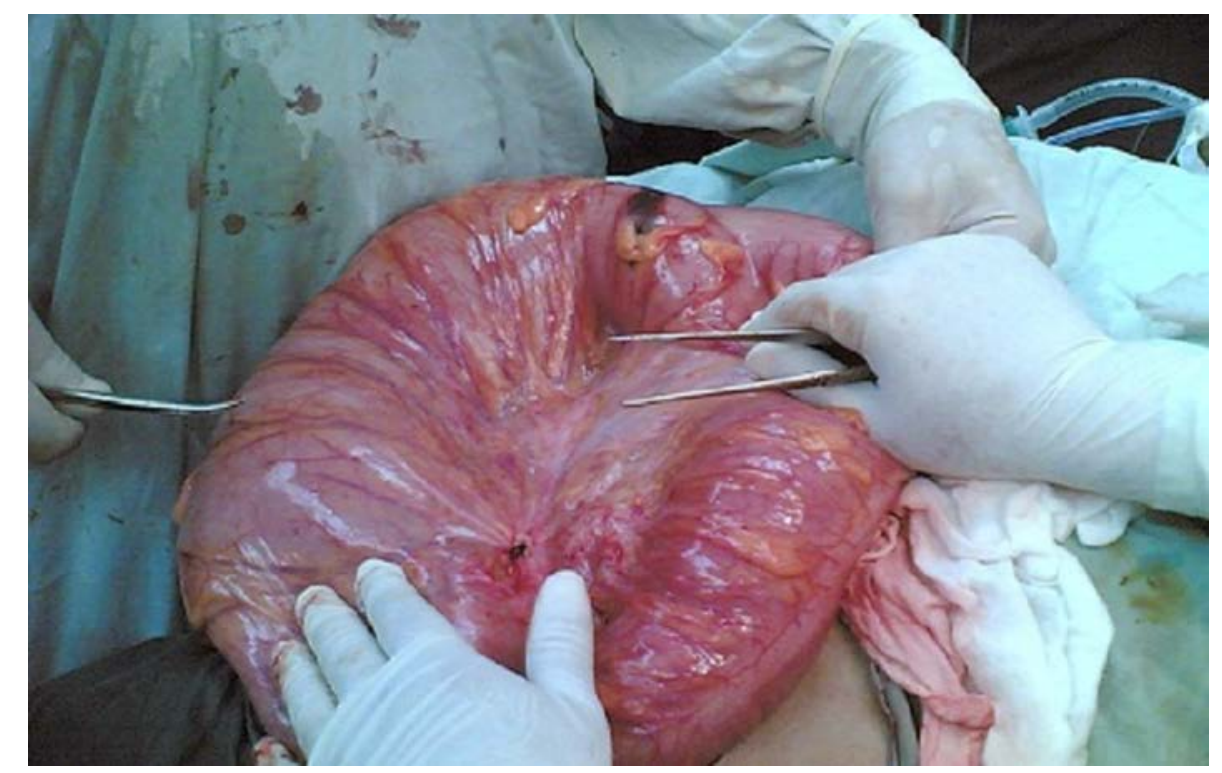

Figure (3): Intra-operative, volvulus of the transverse colon with patch of gangrene.

\section{Discussion:}

Colonic volvulus occurs when the bowel twists around its mesenteric blood supply causing obstruction and ischemic changes. Recognized as far back as the ancient Egyptians' period, ${ }^{1}$ although uncommon in the United States and Western society, it still remains more prominent in the "volvulus belt"; a region extending along Africa, the Middle East, India and Russia. ${ }^{11}$

While sigmoid volvulus accounts for approximately $75 \%$ of cases of colonic volvulus, the caecum is the location of the torsion in $22 \%$, rare sites include transverse colon $2 \%$ and splenic flexure volvulus $1 \% .^{2}$ In this study sigmoid volvulus was $30 / 36$ cases of colonic volvulus, the caecum is $3 / 36$ transverse colon $2 / 36$ and splenic flexure volvulus $1 / 36$. Although the exact cause of volvulus is unknown, multiple different factors likely play a role; high residue diet, narrow attachment, long mesocolon, chronic constipation and band of adhesions are the main predisposing factors, ${ }^{12}$ and so the ratio of length to width of the mesocolon. ${ }^{13} \mathrm{~A}$ neurological origin is also suggested by the finding of increased incidence of volvulus in areas where Chagas disease is prevalent. ${ }^{14}$ Even more interesting is the finding of increased incidence in patients that live in high altitude locations, with the heighest incidences were in Ethiopia, among rural areas of Bolivian and Peruvian Andes. ${ }^{3}$
Regardless of the underlying cause, once this torsion occurs initial venous engorgement followed by lack of arterial flow leads to ischemic changes in the bowel, with eventual necrosis and perforation. 15

Clinical features of volvulus depend, in part, on location of the volvulus as well as the degree of obstruction, and viability of the colon. As such, they vary from chronic dysmotility complaints to acute obstruction and perforation. Most patients with sigmoid volvulus will give a chronic history of constipation and abdominal distension long before the onset of volvulus. This may present more emergently with acute onset of abdominal pain, constipation, and distension, with peritonitis suggesting the presence of ischemia or perforation. ${ }^{16}$ Abdominal examination may show widely variable findings ranging from mild localized tenderness to diffuse peritonitis. Patients may even have a palpable abdominal mass. Rectal examination may be completely normal or demonstrate blood but often there is an absence of stool in the rectal vault. Laboratory examination is often for a leukocytosis and metabolic acidosis, and may also present with significant electrolyte abnormalities. Therefore, identifying those patients at the onset of their clinical course entails a high index of suspicion. ${ }^{17}$ In our series , patients $\mathrm{C} / \mathrm{O}$ nearly from the same i.e. pain was the leading complaint, then abdominal distention and constipation also leucocytosis was a prominent feature in our patients. 
As regard sigmoid volvulus, it is classically described in PXR abdomen by the bent inner tube or coffee bean sign from the dilated airfilled bowel arising from the left lower quadrant and extending towards the diaphragm. Caecal volvulus classically demonstrates a large, gas-filled, ahaustral colon extending from the pelvis in the right lower quadrant to the upper abdomen. ${ }^{18}$

CT may demonstrate a whirl sign in which spiraled loops of collapsed bowel and mesentery are twisted around its vascular supply. In addition, it can demonstrate a closedloop obstruction or concomitant pathology that may have led to the onset of the torsion. ${ }^{19}$

Endoscopy provides information regarding diagnosis, viability of the bowel, as well as therapeutic ability by untwisting of the colon. ${ }^{20}$

Patients should be initially resuscitated with correction of fluid and electrolyte disorders. In addition, broad-spectrum antibiotics to cover aerobic and anaerobic bacteria should be initiated, especially in any patient with a possibility of ischemic bowel.

Treatment options for sigmoid volvulus depend on both the clinical condition of the patient as well as the viability of the bowel. Historically, rectal lavage and saline or barium enemas were used, but increased morbidity and mortality with perforation has largely done away with these methods. Decompression through endoscopy has quickly become a standard initial treatment for these patients. Flexible sigmoidoscopy or colonoscopy has more recently been the preferred method. ${ }^{21}$

A long rectal tube may then be placed proximal to the point of obstruction and left in place for 24-72 hours. ${ }^{22}$

Reduction of the volvulus should, in general, be followed with surgical repair in almost all patients. Surgical options include sigmoidopexy alone, resection with primary anastomosis, and a 2-stage procedure of resection with proximal diversion followed by subsequent takedown depending on both the patient co-morbidities and viability of the bowel. ${ }^{23}$ In our patients, plain X-ray proved a definite diagnosis of sigmoid volvulus by demonstrating coffee bean sign in 8 patients and contrast enema was used in 5 patients which clearly showed the sigmoid volvulus but non of our patients had CT for diagnosis. Decision for operation (Untwisting \& fixation $(n=3)$, resection \& primary anastomosis $(\mathrm{n}=5)$, resection, anastomosis \& covering stoma $(n=10)$ and resection \&colostomy $(\mathrm{n}=12)$, was dependent on intestinal viability, general condition of patient and surgeon's preference.

As in the sigmoid, options for the management of caecal volvulus include: endoscopic decompression versus surgical detorsion alone, caecopexy, caecostomy, and right colectomy with primary or delayed anastomosis or proximal stoma all through open or minimally invasive approaches. ${ }^{20} \mathrm{In}$ our patients, 3 of them had caecal volvulus. All of them were diagnosed intra-operative and right hemicolectomy was done for all of them.

Volvulus associated with the transverse colon or splenic flexure is especially rare. This segment of the colon naturally has limited mobility secondary to the ligamentous attachments at the flexures, thus some or all of these points of fixation must be congenitally missing or surgically altered to predispose its onset. As such, presentation can vary from chronic constipation and recurrent abdominal pain to life-threatening perforation and sepsis. Although colonoscopic decompression is described for both conditions, they are best treated via resection with either an extended right hemicolectomy or left colectomy in those patients with splenic flexure volvulus. ${ }^{24}$

In our case of splenic volvulus, patient had congenital Meckel's diverticulum and abnormally long mesentery of left colon with chronic constipation. This caused internal herniation of left colon \& twist of the colon to cause splenic flexure volvulus.

\section{Conclusion:}

Though volvulus remains an infrequent occurrence, surgeons should remain familiar with the diagnostic evaluation, treatment and expected outcomes. Successful resuscitation entails correction of metabolic disturbances prior to a subsequent operation. Increasing experience has demonstrated the safety and efficacy of resection and anastomosis whether primary or with covering stoma. 


\section{References:}

1- Chadwick J, Mann WN: The medical works of Hippocrates. Springfield: Charles C Thomas; (Publisher); 1967.

2- Ballantyne GH, Brandner MD, Beart Jr RW, et al: Volvulus of the colon: Incidence and mortality. Ann Surg 1985; 202: 83.

3- Asbun HJ, Castellanos H, Balderrama B, et al: Sigmoid volvulus in the high altitude of the Andes: Review of 230 cases. Dis Colon Rectum 1992; 35: 350-353.

4- Buenger RE: Volvulus of the splenic flexure of the colon. AJR 1954, 71: 81-83.

5- Wilk PJ, Ross M: Sigmoid volvulus in an 11-year-old girl. Am J Dis Child 1974; 127 : 400-402.

6- Kuzum A, Aslar AK, Soran A, Polat A, Topcu O, Hengirmen S: Emergent resection for acute sigmoid volvulus: Results of 106 consecutive cases. Dis Colon Rectum 2002; 45: 1085-1090.

7- Dulger M, Canturk NZ, Utkan NZ, Gonullu $\mathrm{NN}$ : Management of sigmoid colon volvulus. Hepatogastroenterology 2000; 47: 1280-1283.

8- Pinedo G, Kirberg A: Percutaneous endoscopic sigmoidopexy in sigmoid volvulus with T-fasteners? Report of two cases. Dis Colon Rectum 2001; 44: 18671869.

9- Chung CC, Kwok SPY, Leung KL, Kwong KH, Lau WY, Li AKC: Laparoscopyassisted sigmoid colectomy for volvulus. Surg Laparosc Endosc 1997; 7 : 423-425.

10-Bhatnagar BNS: Prevention of recurrence of sigmoid colon volvulus: A new approach. A preliminary report. J R Coll Surg Edinb, 1970; $15: 49-52$.

11-Heis HA, Bani-Hani KE, Rabadi DK, et al: Sigmoid volvulus in the Middle East. World J Surg 2008; 32: 459-464.

12-Rains HAJ: Baily \& Loves short practice of surgery. London, UK: Lewis HK (Publisher); 20th edn. 1988; p.1175.

13-Bhatnagar BN, Sharma CL, Gupta SN, et al: Study on the anatomical dimensions of the human sigmoid colon. Clin Anat 2004; 17: 236-243.
14-Gama A, Haddad J, Simonsen O, et al: Volvulus of the sigmoid colon in Brazil: A report of 230 cases. Dis Colon Rectum 1976; 19: 314-320.

15-Gatch WD, Culbertson CG: Circulatory disturbances caused by intestinal obstruction. Ann Surg 1935; 102: 619-635.

16-Avots-Avotins KV, Waugh DE: Colon volvulus and the geriatric patient. Surg Clin North Am 1982; 62: 249-260.

17-Grossmann EM, Johnson FE, Enger KT, Leake BA, Virgo KS, Longo WE: Caecal volvulus: Outcome of management by celiotomy. Tech Coloproctol 1999; 3: 139143.

18-Moore CJ, Corl FM, Fishman EK: CT of caecal volvulus: Unraveling the image. Am J Roentgeol 2001; 177: 95-98.

19-Hashimoto Y, Shigemoto S, Nakashima A, Murakami Y, Sueda T: Successful preoperative diagnosis of a rare bowel obstruction: caecal volvulus. J Gastrointest Surg 2008; 12: 202-204.

20-Gandhi SK, Hanson MM, Vernava AM, Kaminski DL, Longo WE: Ischemic colitis. Dis Colon Rectum 1996; 39: 88-100.

21-Bruusgaard C: Volvulus of the sigmoid colon and its treatment. Surgery 1947; 22 : 466-478.

22-Brothers TE, Strodel WE, Eckhauser FE: Endoscopy in colonic volvulus. Ann Surg 1987; 206: 1-4.

23-Akcan A, Akyildiz H, Artis T, Yilmaz N, Sozuer E: Feasibility of a single-stage resection and primary anastomosis in patients with acute non-complicated sigmoid volvulus. Am J Surg 2007; 193 : 421-426.

24-Mittal R, Samarasam I, Chandran S, Mathew G: Primary splenic flexure volvulus. Singapore Med J 2007; 48(3): 87-89. 